\title{
The translational study of apathy-an ecological approach
}

\author{
Flurin Cathomas ${ }^{1,2 *}$, Matthias N. Hartmann ${ }^{2,3}$, Erich Seifritz ${ }^{2,4}$, Christopher R. Pryce ${ }^{1,4}$ \\ and Stefan Kaiser ${ }^{2,3,5}$ \\ ${ }_{1}^{1}$ Preclinical Laboratory for Translational Research into Affective Disorders (PLaTRAD), Department of Psychiatry, \\ Psychotherapy and Psychosomatics, Psychiatric Hospital, University of Zurich, Zurich, Switzerland, ${ }^{2}$ Department \\ of Psychiatry, Psychotherapy and Psychosomatics, Psychiatric Hospital, University of Zurich, Zurich, Switzerland, \\ ${ }^{3}$ Laboratory for Social and Neural Systems Research, Department of Economics, University of Zurich, Zurich, Switzerland, \\ ${ }^{4}$ Neuroscience Center, Swiss Federal Institute of Technology, University of Zurich, Zurich, Switzerland, ${ }^{5}$ Zurich Center for \\ Integrative Human Physiology, University of Zurich, Zurich, Switzerland
}

OPEN ACCESS

Edited by:

Carmen Sandi,

École Polytechnique Fédérale de

Lausanne, Switzerland

Reviewed by:

Michael Arthur Van Der Kooij,

Johannes Gutenberg University

Mainz, Germany

Fiona Hollis,

École Polytechnique Fédérale de

Lausanne, Switzerland

*Correspondence:

Flurin Cathomas,

Preclinical Laboratory for

Translational Research into Affective Disorders (PLaTRAD), Department of Psychiatry, Psychotherapy and Psychosomatics, Psychiatric Hospital, University of Zurich, Lenggstrasse 31, Postfach 1931, $\mathrm{CH}-8032$ Zurich, Switzerland

flurin.cathomas@puk.zh.ch

Received: 25 April 2015 Accepted: 24 August 2015 Published: 09 September 2015

Citation: Cathomas F, Hartmann MN, Seifritz E, Pryce CR and Kaiser S (2015) The translational study of apathy -an ecological approach

Front. Behav. Neurosci. 9:241. doi: 10.3389/fnbeh.2015.00241
Apathy, a quantitative reduction in goal-directed behavior, is a prevalent symptom dimension with a negative impact on functional outcome in various neuropsychiatric disorders including schizophrenia and depression. The aim of this review is to show that interview-based assessment of apathy in humans and observation of spontaneous rodent behavior in an ecological setting can serve as an important complementary approach to already existing task-based assessment, to study and understand the neurobiological bases of apathy. We first discuss the paucity of current translational approaches regarding animal equivalents of psychopathological assessment of apathy. We then present the existing evaluation scales for the assessment of apathy in humans and propose five sub-domains of apathy, namely self-care, social interaction, exploration, work/education and recreation. Each of the items in apathy evaluation scales can be assigned to one of these sub-domains. We then show that corresponding, well-validated behavioral readouts exist for rodents and that, indeed, three of the five human apathy sub-domains have a rodent equivalent. In conclusion, the translational ecological study of apathy in humans and rodents is possible and will constitute an important approach to increase the understanding of the neurobiological bases of apathy and the development of novel treatments.

\section{Keywords: apathy, schizophrenia, depression, psychopathology, ecological animal models}

\section{Introduction}

Apathy has initially been defined as a lack of motivation (Marin, 1990). Recently, a more behavioral definition has been introduced, defining apathy as a quantitative reduction in goaldirected behavior (Levy and Dubois, 2006). In the present review this latter definition, avoiding the psychological term motivation, will be used because it is much more compatible with the translational approach. Apathy is a prevalent symptom dimension in psychiatric and neurologic disorders (Marin, 1990; Levy and Dubois, 2006; Foussias and Remington, 2010). In psychiatry, it can be observed in schizophrenia (Blanchard and Cohen, 2006), major depression (Marin et al., 1993), and as a consequence of drug abuse (Lynskey and Hall, 2000). In neurological disorders, apathy has been observed independently of other psychiatric symptoms; for example in basal ganglia disease (Levy and Czernecki, 2006; Starkstein et al., 2009), Alzheimer's disease (Starkstein et al., 2001; Robert et al., 2010) and stroke (Jorge et al., 2010; Caeiro et al., 2013). 
Although questions have been raised concerning the nosological status of apathy (Starkstein and Leentjens, 2008), there is unequivocal evidence for its negative impact on the functional outcome of the above mentioned disorders (Kiang et al., 2003; van Reekum et al., 2005; Faerden et al., 2009; Foussias et al., 2009; Konstantakopoulos et al., 2011). Additionally, with the exception of some promising trials with methylphenidate to treat apathy observed in neurological disorders (Devos et al., 2013; Rea et al., 2014), the treatment of apathy remains a rather neglected area of therapeutic research.

Apathy is a symptom dimension that cuts across disease categories. In the present review it is therefore proposed that research into the neurobiological bases and treatment of apathy is best served by regarding it as a domain that is, to a large extent, applicable across traditional nosological categories. In other words, apathy can be considered as a trans-diagnostic clinical phenotype. In addition to, and indeed facilitated by, the conception of apathy as a domain, we propose that understanding of apathy can be increased by integrating its study in human patients with studies in animal models. In contrast to symptoms/domains that have been studied extensively in animal models, with examples including anxiety and helplessness, apathy has become a focus of animal studies only relatively recently, and there has been an almost exclusive focus on discrete behavioral tests rather than the assessment of spontaneous behavior. Based on these considerations in the present review, we: (1) note the current deficits in translational approaches to the study of apathy in the ecological setting; (2) propose five subdomains of apathy that can be measured by psychopathological examination in humans; and (3) demonstrate how assessment of specific animal behaviors can yield analogs for some of these human apathy sub-domains. In other words, we complement existing translational discrete task-based approaches by translating human psychopathological assessments into behavioral observation of spontaneous, on-going animal behavior.

\section{Translating Apathy from Humans to Animal Models}

There has been considerable debate about the challenges of translating progress in behavioral neuroscience to the clinic (Markou et al., 2009; Pryce and Seifritz, 2011; Machado-Vieira, 2012; Braff and Braff, 2013). Consensus is emerging that drug research and development should not be aimed at treating entire categorical disease entities as currently conceptualized, but rather at treating specific symptom dimensions, including those that pertain across neuropsychiatric disorders. As a consequence, translational models comprising manipulations and readout assays that provide animal equivalents of the targeted domains are needed (Markou et al., 2009; Pratt et al., 2012). Indeed, given that it is more realistic to develop an animal model for a specific domain than for an entire nosological disorder, the domain concept also brings the advantage of being contiguous with the translational approach.
Driven largely by its impact on functional outcome and resistance to current treatments, apathy is becoming an increasing focus of psychiatric research (Simpson et al., 2012; Foussias et al., 2015). Interview-based rating scales remain the gold standard in the clinical assessment of apathy. Obviously, a direct translation to animal models is not possible. However, the information obtained through interview-based assessments can, at least in part, be assessed through the observation of spontaneous animal behavior. This approach will be the focus of the present review. Another way used to circumvent these challenges of translational research has involved the establishment of discrete neuropsychological tasks in humans and of equivalent tasks in various animal models (Figure 1). For example, several groups have applied tasks to assess effort-based decisionmaking in humans and animals as a behavioral proxy for motivational deficits (e.g., Gold et al., 2013; Fervaha et al., 2013; Markou et al., 2013; Hartmann et al., 2014; Salamone et al., 2015).

However, pursuing this approach is not straightforward and comprises a number of steps in each species, each of which poses its own challenges and pitfalls. The first step is the development of appropriate tasks to assess apathy in humans. While tasks have been considered to be "objective" and thus preferable, interviewbased assessment with rating scales remain the gold standard in the assessment of apathy and the measure against which all newly developed tasks are tested. The second step concerns the development of tasks that are analogs in humans and model species with respect to the neurobehavioral processes they are measuring. The third step is the animal model equivalent of step one described above for humans, namely, interpretation of task performance in terms of what it implies about their spontaneous, on-going behavior in the home-cage. Does an animal that exhibit low goal-directed behavior in a discrete task also exhibit decreased performance of spontaneous behaviors in its home environment? Although one could argue that task behavior in itself is enough, validity of the ecological approach would be markedly increased if task performance had similar relationships to "real-world" behavior, both in humans and animal models.

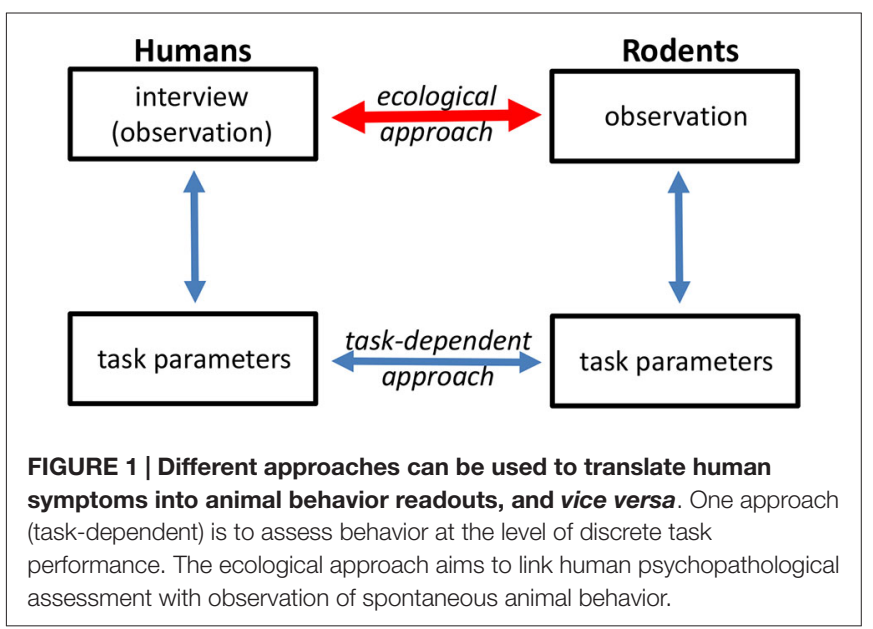


In the present review, we propose an ecological approach, as an important complement to discrete tasks, to the development of translational assays for apathy, based on linking human psychopathological assessment and the observation of spontaneous animal behavior. We propose five sub-domains of apathy, some of which can be observed and quantified in laboratory model animals.

\section{Sub-Domains of Apathy in Humans}

In this section, we will briefly introduce approaches to the assessment of apathy in humans. As mentioned above, interviewbased rating scales remain the gold standard for the assessment of apathy, but have been complemented by self-ratings and observer-ratings. Based on the items used to assess apathy, we propose a five sub-domain schema.

Scales aiming at the exclusive assessment of apathy have mainly been developed for patients with neurological disorders, such as the Apathy Evaluation Scale (AES; Marin et al., 1991). However, the AES has also been used to assess apathy in schizophrenia and depression (Faerden et al., 2008; Raskin et al., 2012). While the scale items themselves do not specify subdomains of apathy, the accompanying manual suggests some domains for assessing interest and activities, e.g., hobbies, work or activities with other people.

In patients with primary psychiatric disorders apathy is usually addressed in the context of a broader negative symptom assessment, such as the Scale for the Assessment of Negative Symptoms (SANS; Andreasen, 1989). Factor analytic studies have demonstrated that these instruments assess two different factors-apathy/avolition and diminished expression (Messinger et al., 2011). The Brief Negative Symptom Scale (BNSS; Kirkpatrick et al., 2011) and the Clinical Assessment Interview for Negative Symptoms (CAINS; Kring et al., 2013) are two recent instruments that reflect this two-factor structure even more clearly. In all these instruments the assessment of apathy relies on the elicitation of reports on activities in the domains work, recreation, social/sexual interest, exploration and selfcare.

While interview-based scales remain the standard for assessment of apathy in humans, there are some inherent limitations. For example, the retrospective reporting by the patient regarding his activities and mental state during a certain time frame might lack reliability. To circumvent this problem, observer-based measures have been employed. For the AES a carer version is available that can be completed by professional and non-professional caregivers (Marin et al., 1991). For inpatient settings, Trémeau et al. (2012) have introduced a measure based on constant observation. Importantly, all these observation-based measures address the same sub-domains of apathy as the interview-based scales, although opportunities for activities are more limited in inpatient settings. In addition, newer technologies facilitate real-time assessment of patients' behavior and associated internal states (Oorschot et al., 2009), but have not yet been applied to the study of apathy.

A primary goal of current rating scales to assess apathy is the estimation of goal-directed behavior in a wide array of life domains. Based on the domains assessed in interview- and observer-based rating scales, we propose five sub-domains in which a reduction of goal-directed behavior is frequently observed in apathetic patients, namely: self-care, exploration, social interaction, work/education, and recreation.

\section{Apathy in Laboratory Animals}

In the current section, we discuss the potential of applying observational measurement of spontaneous behavior in mice to the translational study of apathy. The different behaviors identified are considered in the framework of the five subdomains of apathy in humans (Table 1). For each behavior, an example of a manipulation that impacted on the behavior to induce changes relevant to the corresponding sub-domain, is presented. The discussion is limited to rodents, but should certainly be extended to other species studied in the laboratory.

\section{Nest Construction}

Self-care is an important sub-domain of apathy in humans and includes activities related to the patient's home, such as cleaning or looking for a place to live (Table 1). Nest construction is common across many animal species and is important for heat conservation, reproduction and as a protective place against predators (Latham and Mason, 2004). Several scales with which to rate nest construction have been proposed. A comprehensive scale was created by Deacon (Deacon, 2006) consisting of a five-point rating scale, aimed at assessing the quality of the nest.

It was shown that the sub-chronic administration of phencyclidine, which is well-characterized as a pharmacological inducer of schizophrenia-relevant behaviors in animals, impaired nest building in mice (Pedersen et al., 2014). The deficit was quantified by a scoring system ("Nesting Index Score"), where the quality of the nest was assessed every hour. The deficit was attenuated by acute treatment with a nicotine alpha7

TABLE 1 | Assignment of the different human and animal psychopathological assessments/observations to the different sub-domains of apathy.

\begin{tabular}{lll}
\hline & Human & Rodent \\
\hline Self-care & Neglected personal hygiene & $\begin{array}{l}\text { Impaired nest } \\
\text { construction } \\
\text { Disturbed self-grooming }\end{array}$ \\
& $\begin{array}{l}\text { Neglected clothing } \\
\text { Reduced care for place to live }\end{array}$ & \\
Social interaction & $\begin{array}{l}\text { Reduced participation in } \\
\text { activities with other people }\end{array}$ & Reduced maternal care \\
& $\begin{array}{l}\text { Reduced discussion of personal } \\
\text { matters with others }\end{array}$ & $\begin{array}{l}\text { Reduced interest in same } \\
\text { and opposite }\end{array}$ \\
& $\begin{array}{l}\text { Reduced sexual interest } \\
\text { and activity }\end{array}$ & sex-conspecifics \\
Impaired novelty seeking & Impaired interest in \\
Exploration & neduced interest and & - \\
Recreation & $\begin{array}{l}\text { Revects } \\
\text { engagement in recreational } \\
\text { activities } \\
\text { Reduced interest and activity }\end{array}$ & \\
in work/education & -
\end{tabular}


receptor agonist (the same compound has been reported to exert beneficial effects on negative symptoms in schizophrenia patients; Hashimoto, 2015), but not with risperidone, an atypical antipsychotic.

\section{Self-Grooming}

Another aspect of self-care in humans includes personal hygiene, which is often impaired in patients with apathy (Table 1). The rodent equivalent is self-grooming and accounts for 30-50\% of the waking time of rodents (Bolles, 1960). The main function of self-grooming is to clean in order to maintain health, e.g., by removing detritus and disease-carrying parasites. Other functions of self-grooming include thermoregulation, stimulation of pheromone release and self-stimulation (Spruijt et al., 1992). In rodents, self-grooming consists of a repeated behavior with a sequential cephalocaudal progression (Kalueff and Tuohimaa, 2004). The usual method for measuring selfgrooming is by observation and quantification of duration, frequency and inter-bout intervals of self-grooming elements (Kalueff and Tuohimaa, 2004). In addition, complex algorithms exist for detailed descriptions of repeated self-grooming sequences using a computer-assisted scoring system (Kalueff et al., 2007).

Denmark et al. (2010) showed that chronic social defeat stress (CSDS) leads to disorganized patterning of grooming behaviors in subordinate mice. CSDS is a widely applied manipulation in rodent research and it is based on the finding that specific uncontrollable stressful life events are major aetiological factors in various neuropsychiatric disorders. It was shown that CSDS affects dopamine function in specific brain regions, e.g., downregulated expression of genes for dopamine receptors and signaling proteins (Azzinnari et al., 2014).

\section{Interest in Same and Opposite-Sex Conspecifics}

Social withdrawal or asociality is a key component of apathy in humans that includes interaction with family and friends as well as sexual interest and activity (Table 1). Rodents exhibit a complex repertoire of social behaviors (Grant and Mackintosh, 1963). One of the methods to test interest in samesex conspecifics in mice is the three-chambered social approach test, initially developed as a discrete test, it can also be applied in the home-cage setting (Yang et al., 2011): the home-cage is separated into three parts and the rodent can move from one part to another. In one outer compartment there is a wire cage containing an unfamiliar conspecific and in the opposite outer compartment there is an empty wire cage (Nadler et al., 2004). Measures that can be obtained include time spent in the compartment containing the novel subject compared to time in the empty compartment (Yang et al., 2011).

A large number of behaviors can be measured to assess sociosexual and copulatory behavior: sniffing (e.g., total duration of anogentital sniffing), number of male mounts (defined as male using both forepaws to climb onto a female from behind for copulation but without achieving penetration), female lordosis (all four paws rounded, the hind region elevated from the floor), intromission (two or more thrusts with penetration) and ejaculation (Huber et al., 1980; Farmer et al., 2014).
The bilateral depletion of dopamine in the medial prefrontal cortex (mPFC) through infusion of 6-hydroxydopamine (6OHDA) in adult and adolescent rats led to reduced social interactions (e.g., sniffing time) compared to controls ( $\mathrm{Li}$ et al., 2010). The 6-OHDA-mPFC lesion model of dopaminergic neurons is based on the findings that there is a correlation between hypodopaminergic functioning in the PFC and negative symptoms (Howes and Kapur, 2009).

\section{Maternal Care}

Another aspect of social interaction is maternal care, which is not included in routine assessment of apathy. However, apathetic behavior towards newborn infants is an important issue in mothers suffering from schizophrenia and other psychiatric disorders (Matevosyan, 2011). Also in rodents, maternal care-the nurturant behavior of the dam towards its offspring-is one of the most complex social relationships (Lonstein and De Vries, 2000). It consists of different behaviors that can be separately assessed (Lonstein and Fleming, 2002; Kuroda and Tsuneoka, 2013): (A) Retrieval: the mother picking up a pup in its mouth and transporting it to the nest; (B) Pup licking: the functions of pup licking are to clean, increase activity and facilitate elimination of waste; and (C) Time spent crouching over and nursing pups: the mother is positioned over the pups and is either active (licking the pups, nursing, self-grooming, moving nest material) or quiescent (induced by the suckling of the pups).

Examples of effects of schizophrenia-relevant manipulations on maternal care include a study in mice where maternal behavior (e.g., the latency to retrieve pups) was impaired by genetic deletion of the endocannabinoid receptor-1 (Schechter et al., 2013). In human patients, long-term cannabis use is associated with apathy (Looby and Earleywine, 2007) and an imaging study identified an inverse relationship between striatal dopamine synthesis capacity and apathy (measured with the AES; Bloomfield et al., 2014).

\section{Novel Object Exploration Test}

Exploration can be defined as behavior that is elicited by novel stimuli and allows for the collection of information about unfamiliar elements of the environment (Crusio and van Abeelen, 1986). The reduction of interest in novel experiences, including attenuated exploration, is an indicator of human apathy (Table 1). In rodents, novelty is arousing and stimulates exploration. Whenever a novel stimulus is presented alongside a familiar one, there is typically more exploration of the novel stimulus until the stimulus loses its novelty (Ennaceur, 2010). There are different modifications of the novel object exploration (or preference) test based on the same principle: Rodents are exposed to both familiar and novel objects (e.g., in their home-cages) and allowed to explore them freely (Pearson et al., 2011; Blick et al., 2014). The interaction time of the subject with the novel object is measured and compared to the time spent with the familiar object (Heyser and Chemero, 2012).

It was shown in mice that a compound with selective partial agonist effects to the dopamine D4 receptor and minimal affinity 
for dopamine D2 and D3 receptors increased time spent near a novel object compared to controls (Powell et al., 2003).

\section{Conclusion and Implications for Future Research}

Apathy, which is defined in the present review as a quantitative reduction in goal-directed behavior, is a prevalent symptom dimension that cuts across disease categories and has a negative impact on the functional outcome of many neuropsychiatric disorders including schizophrenia and depression. Translational studies in humans and animal models are an important approach to disentangle the underlying neurobiological mechanisms. Recently, considerable effort has been made in the assessment of apathy via task performances (e.g., effort-based decisionmaking). While this approach is indeed interesting and promising, the assessment of apathy in humans through rating scales remains the gold standard. We therefore propose a complementary approach by using the clinical interviews as a starting point and show that the items can be synthesized into five sub-domains in humans and that three of these can also be assessed in rodents.

Apathy is clearly not unique in being conducive to this approach. Another example would be sleep disturbance, as is common in many neuropsychiatric disorders, for which there are several detailed human assessment scales (e.g., the

\section{References}

Andreasen, N. C. (1989). The Scale for the Assessment of Negative Symptoms (SANS): conceptual and theoretical foundations. Br. J. Psychiatry Suppl. 7, $49-58$.

Azzinnari, D., Sigrist, H., Staehli, S., Palme, R., Hildebrandt, T., Leparc, G., et al. (2014). Mouse social stress induces increased fear conditioning, helplessness and fatigue to physical challenge together with markers of altered immune and dopamine function. Neuropharmacology 85, 328-341. doi: 10.1016/j. neuropharm.2014.05.039

Blanchard, J. J., and Cohen, A. S. (2006). The structure of negative symptoms within schizophrenia: implications for assessment. Schizophr. Bull. 32, 238-245. doi: 10.1093/schbul/sbj013

Blick, M. G., Puchalski, B. H., Bolanos, V. J., Wolfe, K. M., Green, M. C., and Ryan, B. C. (2014). Novel object exploration in the C58/J mouse model of autistic-like behavior. Behav. Brain Res. 282, 54-60. doi: 10.1016/j.bbr.2014.12.030

Bloomfield, M. A., Morgan, C. J., Kapur, S., Curran, H. V., and Howes, O. D. (2014). The link between dopamine function and apathy in cannabis users: an [18F]-DOPA PET imaging study. Psychopharmacology (Berl) 231, 2251-2259. doi: 10.1007/s00213-014-3523-4

Bolles, R. C. (1960). Grooming behavior in the rat. J. Comp. Physiol. Psychol. 53, 306-310. doi: 10.1037/h0045421

Braff, L., and Braff, D. L. (2013). The neuropsychiatric translational revolution still very early and still very challenging. JAMA Psychiatry 70, 777-779. doi: 10. 1001/jamapsychiatry.2013.2184

Buysse, D. J., Reynolds, C. F.IIIrd, Monk, T. H., Berman, S. R., and Kupfer, D. J. (1989). The pittsburgh sleep quality index: a new instrument for psychiatric practice and research. Psychiatry Res. 28, 193-213. doi: 10. 1016/0165-1781(89)90047-4

Caeiro, L., Ferro, J. M., and Costa, J. (2013). Apathy secondary to stroke: a systematic review and meta-analysis. Cerebrovasc. Dis. 35, 23-39. doi: 10. $1159 / 000346076$

Cathomas, F., Stegen, M., Sigrist, H., Schmid, L., Seifritz, E., Gassmann, M., et al. (2015). Altered emotionality and neuronal excitability in mice lacking
Pittsburgh Sleep Quality Index; Buysse et al., 1989) as well as methods of quantification in animal models (e.g., homecage monitoring systems; Cathomas et al., 2015) available. In conclusion, we propose that future efforts of translational assessment of apathy in humans and animal models should include behavioral readouts based on interview/observational measures, preferably conducted in the real-life/home-cage. The next step in the development of this approach will be to demonstrate that the readouts in humans and animals are sensitive to the same manipulation. For example, administration of a dopamine-receptor modulating compound could be investigated for effects on the proposed sub-domains of apathy, e.g., assessing self-care in humans using the SANS and self-grooming in mice. This approach, in combination with task-based assessments, should lead to improved face validity of animal apathy models and can then be applied to assess the effects of relevant genetic, environmental and pharmacological manipulations to increase understanding of the neurobiological bases of apathy and for the development of new treatments.

\section{Acknowledgments}

This research was funded by the Swiss National Science Foundation (grant 31003A-141137) and the Hartmann Müller Foundation.

KCTD12, an auxiliary subunit of GABAB receptors associated with mood disorders. Transl. Psychiatry 5:e510. doi: 10.1038/tp.2015.8

Crusio, W. E., and van Abeelen, J. H. (1986). The genetic architecture of behavioural responses to novelty in mice. Heredity (Edinb) 56, 55-63. doi: 10. 1038/hdy. 1986.8

Deacon, R. M. (2006). Assessing nest building in mice. Nat. Protoc. 1, 1117-1119. doi: $10.1038 /$ nprot.2006.170

Denmark, A., Tien, D., Wong, K., Chung, A., Cachat, J., Goodspeed, J., et al. (2010). The effects of chronic social defeat stress on mouse self-grooming behavior and its patterning. Behav. Brain Res. 208, 553-559. doi: 10.1016/j.bbr. 2009.12.041

Devos, D., Moreau, C., Delval, A., Dujardin, K., Defebvre, L., and Bordet, R. (2013). Methylphenidate: a treatment for parkinson's disease? CNS Drugs 27, 1-14. doi: 10.1007/s40263-012-0017-y

Ennaceur, A. (2010). One-trial object recognition in rats and mice: methodological and theoretical issues. Behav. Brain Res. 215, 244-254. doi: 10.1016/j.bbr.2009. 12.036

Faerden, A., Nesvåg, R., Barrett, E. A., Agartz, I., Finset, A., Friis, S., et al. (2008). Assessing apathy: the use of the apathy evaluation scale in first episode psychosis. Eur. Psychiatry 23, 33-39. doi: 10.1016/j.eurpsy.2007. 09.002

Faerden, A., Vaskinn, A., Finset, A., Agartz, I., Ann Barrett, E., Friis, S., et al. (2009). Apathy is associated with executive functioning in first episode psychosis. BMC Psychiatry 9:1. doi: 10.1186/1471-244x-9-1

Farmer, M. A., Leja, A., Foxen-Craft, E., Chan, L., Macintyre, L. C., Niaki, T., et al (2014). Pain reduces sexual motivation in female but not male mice. J. Neurosci. 34, 5747-5753. doi: 10.1523/JNEUROSCI.5337-13.2014

Fervaha, G., Graff-Guerrero, A., Zakzanis, K. K., Foussias, G., Agid, O., and Remington, G. (2013). Incentive motivation deficits in schizophrenia reflect effort computation impairments during cost-benefit decision-making. J. Psychiatr. Res. 47, 1590-1596. doi: 10.1016/j.jpsychires.2013.08.003

Foussias, G., Mann, S., Zakzanis, K. K., van Reekum, R., and Remington, G. (2009). Motivational deficits as the central link to functioning in schizophrenia: a pilot study. Schizophr. Res. 115, 333-337. doi: 10.1016/j.schres.2009.09.020 
Foussias, G., and Remington, G. (2010). Negative symptoms in schizophrenia: avolition and occam's razor. Schizophr. Bull. 36, 359-369. doi: 10. 1093/schbul/sbn094

Foussias, G., Siddiqui, I., Fervaha, G., Agid, O., and Remington, G. (2015). Dissecting negative symptoms in schizophrenia: opportunities for translation into new treatments. J. Psychopharmacol. 29, 116-126. doi: 10. $1177 / 0269881114562092$

Gold, J. M., Strauss, G. P., Waltz, J. A., Robinson, B. M., Brown, J. K., and Frank, M. J. (2013). Negative symptoms of schizophrenia are associated with abnormal effort-cost computations. Biol. Psychiatry 74, 130-136. doi: 10.1016/j.biopsych. 2012.12.022

Grant, E. C., and Mackintosh, J. H. (1963). A comparison of the social postures of some common laboratory rodents. Behav. 21, 246-259. doi: 10. $1163 / 156853963 \times 00185$

Hartmann, M. N., Hager, O. M., Reimann, A. V., Chumbley, J. R., Kirschner, M., Seifritz, E., et al. (2014). Apathy but not diminished expression in schizophrenia is associated with discounting of monetary rewards by physical effort. Schizophr. Bull. 503, 503-512. doi: 10.1093/schbul/sbu102

Hashimoto, K. (2015). Targeting of $\alpha 7$ nicotinic acetylcholine receptors in the treatment of schizophrenia and the use of auditory sensory gating as a translational biomarker. Curr. Pharm. Des. 21, 3797-3806. doi: 10 . 2174/1381612821666150605111345

Heyser, C. J., and Chemero, A. (2012). Novel object exploration in mice: not all objects are created equal. Behav. Processes 89, 232-238. doi: 10.1016/j.beproc. 2011.12.004

Howes, O. D., and Kapur, S. (2009). The dopamine hypothesis of schizophrenia: version III--the final common pathway. Schizophr. Bull. 35, 549-562. doi: 10. 1093/schbul/sbp006

Huber, M. H., Bronson, F. H., and Desjardins, C. (1980). Sexual activity of aged male mice: correlation with level of arousal, physical endurance, pathological status and ejaculatory capacity. Biol. Reprod. 23, 305-316. doi: 10. 1095/biolreprod23.2.305

Jorge, R. E., Starkstein, S. E., and Robinson, R. G. (2010). Apathy following stroke. Can. J. Psychiatry 55, 350-354.

Kalueff, A. V., Aldridge, J. W., LaPorte, J. L., Murphy, D. L., and Tuohimaa, P. (2007). Analyzing grooming microstructure in neurobehavioral experiments. Nat. Protoc. 2, 2538-2544. doi: 10.1038/nprot.2007.367

Kalueff, A. V., and Tuohimaa, P. (2004). Grooming analysis algorithm for neurobehavioural stress research. Brain Res. Brain Res. Protoc. 13, 151-158. doi: 10.1016/j.brainresprot.2004.04.002

Kiang, M., Christensen, B. K., Remington, G., and Kapur, S. (2003). Apathy in schizophrenia: clinical correlates and association with functional outcome. Schizophr. Res. 63, 79-88. doi: 10.1016/s0920-9964(02)00433-4

Kirkpatrick, B., Strauss, G. P., Nguyen, L., Fischer, B. A., Daniel, D. G., Cienfuegos, A., et al. (2011). The brief negative symptom scale: psychometric properties. Schizophr. Bull. 37, 300-305. doi: 10.1093/schbul/sbq059

Konstantakopoulos, G., Ploumpidis, D., Oulis, P., Patrikelis, P., Soumani, A., Papadimitriou, G. N., et al. (2011). Apathy, cognitive deficits and functional impairment in schizophrenia. Schizophr. Res. 133, 193-198. doi: 10.1016/j. schres.2011.07.003

Kring, A. M., Gur, R. E., Blanchard, J. J., Horan, W. P., and Reise, S. P. (2013). The Clinical Assessment Interview for Negative Symptoms (CAINS): final development and validation. Am. J. Psychiatry 170, 165-172. doi: 10.1176/appi. ajp.2012.12010109

Kuroda, K. O., and Tsuneoka, Y. (2013). Assessing postpartum maternal care, alloparental behavior and infanticide in mice: with notes on chemosensory influences. Methods Mol. Biol. 1068, 331-347. doi: 10.1007/978-1-62703-619$1 \_25$

Latham, N., and Mason, G. (2004). From house mouse to mouse house: the behavioural biology of free-living Mus musculus and its implications in the laboratory. App. Anim. Behav. Sci. 86, 261-289. doi: 10.1016/j.applanim.2004. 02.006

Levy, R., and Czernecki, V. (2006). Apathy and the basal ganglia. J. Neurol. 253(Suppl. 7), VII54-VII61. doi: 10.1007/s00415-006-7012-5

Levy, R., and Dubois, B. (2006). Apathy and the functional anatomy of the prefrontal cortex-basal ganglia circuits. Cereb. Cortex 16, 916-928. doi: 10. 1093/cercor/bhj043

Li, C. R., Huang, G. B., Sui, Z. Y., Han, E. H., and Chung, Y. C. (2010). Effects of 6-hydroxydopamine lesioning of the medial prefrontal cortex on social interactions in adolescent and adult rats. Brain Res. 1346, 183-189. doi: 10 1016/j.brainres.2010.05.064

Lonstein, J. S., and De Vries, G. J. (2000). Sex differences in the parental behavior of rodents. Neurosci. Biobehav. Rev. 24, 669-686. doi: 10.1016/s01497634(00)00036-1

Lonstein, J. S., and Fleming, A. S. (2002). Parental behaviors in rats and mice. Curr. Protoc. Neurosci.Chapter 8, Unit 8 15. doi: 10.1002/0471142301.ns0815s17

Looby, A., and Earleywine, M. (2007). Negative consequences associated with dependence in daily cannabis users. Subst. Abuse Treat. Prev. Policy 2:3. doi: 10. 1186/1747-597X-2-3

Lynskey, M., and Hall, W. (2000). The effects of adolescent cannabis use on educational attainment: a review. Addiction 95, 1621-1630. doi: 10.1046/j.13600443.2000.951116213.x

Machado-Vieira, R. (2012). Tracking the impact of translational research in psychiatry: state of the art and perspectives. J. Transl. Med. 10:175. doi: 10 1186/1479-5876-10-175

Marin, R. S. (1990). Differential diagnosis and classification of apathy. Am. J. Psychiatry 147, 22-30. doi: 10.1176/ajp.147.1.22

Marin, R. S., Biedrzycki, R. C., and Firinciogullari, S. (1991). Reliability and validity of the apathy evaluation scale. Psychiatry Res. 38, 143-162. doi: 10.1016/01651781(91)90040-v

Marin, R. S., Firinciogullari, S., and Biedrzycki, R. C. (1993). The sources of convergence between measures of apathy and depression. J. Affect. Disord. 28, 117-124. doi: 10.1016/0165-0327(93)90040-q

Markou, A., Chiamulera, C., Geyer, M. A., Tricklebank, M., and Steckler, T. (2009). Removing obstacles in neuroscience drug discovery: the future path for animal models. Neuropsychopharmacology 34, 74-89. doi: 10.1038/npp.2008.173

Markou, A., Salamone, J. D., Bussey, T. J., Mar, A. C., Brunner, D., Gilmour, G., et al. (2013). Measuring reinforcement learning and motivation constructs in experimental animals: relevance to the negative symptoms of schizophrenia. Neurosci. Biobehav. Rev. 37, 2149-2165. doi: 10.1016/j.neubiorev.2013. 08.007

Matevosyan, N. R. (2011). Pregnancy and postpartum specifics in women with schizophrenia: a meta-study. Arch. Gynecol. Obstet. 283, 141-147. doi: 10. 1007/s00404-010-1706-8

Messinger, J. W., Tremeau, F., Antonius, D., Mendelsohn, E., Prudent, V., Stanford, A. D., et al. (2011). Avolition and expressive deficits capture negative symptom phenomenology: implications for DSM-5 and schizophrenia research. Clin. Psychol. Rev. 31, 161-168. doi: 10.1016/j.cpr.2010.09.002

Nadler, J. J., Moy, S. S., Dold, G., Trang, D., Simmons, N., Perez, A., et al. (2004). Automated apparatus for quantitation of social approach behaviors in mice. Genes Brain Behav. 3, 303-314. doi: 10.1111/j.1601-183x.2004.00071.x

Oorschot, M., Kwapil, T., Delespaul, P., and Myin-Germeys, I. (2009). Momentary assessment research in psychosis. Psychol. Assess. 21, 498-505. doi: 10. 1037/a0017077

Pearson, B. L., Pobbe, R. L., Defensor, E. B., Oasay, L., Bolivar, V. J., Blanchard, D. C., et al. (2011). Motor and cognitive stereotypies in the BTBR T+tf/J mouse model of autism. Genes Brain Behav. 10, 228-235. doi: 10.1111/j.1601-183x. 2010.00659.x

Pedersen, C. S., Sørensen, D. B., Parachikova, A. I., and Plath, N. (2014). PCPinduced deficits in murine nest building activity: employment of an ethological rodent behavior to mimic negative-like symptoms of schizophrenia. Behav. Brain Res. 273, 63-72. doi: 10.1016/j.bbr.2014.07.023

Powell, S. B., Paulus, M. P., Hartman, D. S., Godel, T., and Geyer, M. A. (2003). RO-10-5824 is a selective dopamine D4 receptor agonist that increases novel object exploration in C57 mice. Neuropharmacology 44, 473-481. doi: 10. 1016/s0028-3908(02)00412-4

Pratt, J., Winchester, C., Dawson, N., and Morris, B. (2012). Advancing schizophrenia drug discovery: optimizing rodent models to bridge the translational gap. Nat. Rev. Drug Discov. 11, 560-579. doi: 10.1038/nrd3649

Pryce, C. R., and Seifritz, E. (2011). A translational research framework for enhanced validity of mouse models of psychopathological states in depression. Psychoneuroendocrinology 36, 308-329. doi: 10.1016/j.psyneuen.2010. 05.003

Raskin, J., George, T., Granger, R. E., Hussain, N., Zhao, G. W., and Marangell, L. B. (2012). Apathy in currently nondepressed patients treated with a SSRI for a major depressive episode: outcomes following randomized switch to either duloxetine or escitalopram. J. Psychiatr. Res. 46, 667-674. doi: 10.1016/j. jpsychires.2012.02.010 
Rea, R., Carotenuto, A., Fasanaro, A. M., Traini, E., and Amenta, F. (2014). Apathy in Alzheimer's disease: any effective treatment? Scientific World Journal 2014, 1-9. doi: 10.1155/2014/421385

Robert, P. H., Mulin, E., Malléa, P., and David, R. (2010). REVIEW: Apathy diagnosis, assessment and treatment in Alzheimer's disease. CNS Neurosci. Ther. 16, 263-271. doi: 10.1111/j.1755-5949.2009.00132.x

Salamone, J. D., Koychev, I., Correa, M., and McGuire, P. (2015). Neurobiological basis of motivational deficits in psychopathology. Eur. Neuropsychopharmacol. 25, 1225-1238. doi: 10.1016/j.euroneuro.2014.08.014

Schechter, M., Weller, A., Pittel, Z., Gross, M., Zimmer, A., and Pinhasov, A. (2013). Endocannabinoid receptor deficiency affects maternal care and alters the dam's hippocampal oxytocin receptor and brain-derived neurotrophic factor expression. J. Neuroendocrinol. 25, 898-909. doi: 10.1111/jne.12082

Simpson, E. H., Waltz, J. A., Kellendonk, C., and Balsam, P. D. (2012). Schizophrenia in translation: dissecting motivation in schizophrenia and rodents. Schizophr. Bull. 38, 1111-1117. doi: 10.1093/schbul/sbs114

Spruijt, B. M., van Hooff, J. A., and Gispen, W. H. (1992). Ethology and neurobiology of grooming behavior. Physiol. Rev. 72, 825-852.

Starkstein, S. E., and Leentjens, A. F. (2008). The nosological position of apathy in clinical practice. J. Neurol. Neurosurg. Psychiatry 79, 1088-1092. doi: 10. 1136/jnnp.2007.136895

Starkstein, S. E., Merello, M., Jorge, R., Brockman, S., Bruce, D., and Power, B. (2009). The syndromal validity and nosological position of apathy in parkinson's disease. Mov. Disord. 24, 1211-1216. doi: 10.1002/mds.22577
Starkstein, S. E., Petracca, G., Chemerinski, E., and Kremer, J. (2001). Syndromic validity of apathy in Alzheimer's disease. Am. J. Psychiatry 158, 872-877. doi: 10.1176/appi.ajp.158.987.872

Trémeau, F., Nolan, K. A., Malaspina, D., and Javitt, D. C. (2012). Behavioral validation of avolition in schizophrenia. Schizophr. Res. 138, 255-261. doi: 10 1016/j.schres.2012.02.018

van Reekum, R., Stuss, D. T., and Ostrander, L. (2005). Apathy: why care? J. Neuropsychiatry Clin. Neurosci. 17, 7-19. doi: 10.1176/appi.neuropsych. 17.1.7

Yang, M., Silverman, J. L., and Crawley, J. N. (2011). Automated three-chambered social approach task for mice. Curr. Protoc. Neurosci. Chapter 8, Unit 826. doi: 10.1002/0471142301.ns0826s56

Conflict of Interest Statement: The authors declare that the research was conducted in the absence of any commercial or financial relationships that could be construed as a potential conflict of interest.

Copyright (c) 2015 Cathomas, Hartmann, Seifritz, Pryce and Kaiser. This is an openaccess article distributed under the terms of the Creative Commons Attribution License (CC BY). The use, distribution and reproduction in other forums is permitted, provided the original author(s) or licensor are credited and that the original publication in this journal is cited, in accordance with accepted academic practice. No use, distribution or reproduction is permitted which does not comply with these terms. 